\title{
REFLEXÃO SOBRE AS CONSEQUÊNCIAS E A REPERCUSSÃO DA EDUCAÇÃO A DISTÂNCIA (EaD) ${ }^{1}$
}

\author{
REFLECTION ABOUT THE REPERCUSSION AND \\ CONSEQUENCES OF LONG DISTANCE EDUCATION (EAD)
}

\begin{abstract}
Regina Machado ${ }^{2}$
Alexandre Pinto ${ }^{3}$
\end{abstract}

RESUMO:

Este artigo pretende descrever sobre as consequências e a repercussão do ensino na modalidade a distância (EaD). Cujo objetivo principal é mapear os pontos relevantes e as lacunas desta modalidade, como indicativo para melhorias futuras. As fontes utilizadas para o desenvolvimento deste estudo foram os depoimentos de tutores do $\mathrm{EaD}$, suas experiências, suas técnicas e a temática desenvolvida nos cursos, assim como, o aproveitamento dos estudantes do EaD. Nesse sentido procurou-se focar os seguintes questionamentos: Quais os pontos fracos e fortes do EaD? Qual o nível de aproveitamento dos estudantes? Através desta linha de questionamento pretende-se mostrar a contribuição da modalidade do ensino a distância, que vem assumindo múltiplas formas, propõe novas questões de ordem institucional, social e pedagógica. O método utilizado foi uma análise qualitativa. Considerando que a pesquisa qualitativa é a forma mais conveniente para tratar da problemática de caráter social, principalmente quando envolve pessoas, ensino, educação, comunicação e informação. Portanto chegou-se a conclusão que apesar de todo aparato tecnológico que envolve o $\mathrm{EaD}$, esta modalidade de ensino/aprendizagem encontra-se ainda fragilizada em consequência da grande demanda. Nessa concepção deve-se adentrar no legado da certificação do ensino/aprendizagem no ambiente virtual como um construto subjetivo, que está diretamente relacionado com a capacitação e o desempenho cognitivo dos sujeitos

\footnotetext{
${ }^{1}$ Trabalho apresentado no SIED/EnPED 2012.

${ }^{2}$ Doutoranda em Metodologia e Linhas de Investigação em Biblioteconomia e Documentação pela Universidade de Salamanca na Espanha; Graduada em Letras pela UNICAP-PE; Graduada em Biblioteconomia pela UFPE. Assistente em C\&T (FUNDAJ) -E-mail:reginamachado4@hotmail.com; regina.machado@fundaj.gov.br.

3 Engenheiro Agrônomo (UFRP-PE); Mestre em Geografia (UFPE); Assistente em Pesquisa e Tecnologia (FUNDAJ) - E-mail: alexbpinto@yahoo.com.br; alexandre.pinto@fundaj.gov.br.
} 
sociais, que consequentemente transforma-se em capital cultural. Porque pior do que não existir uma sociedade capacitada preparada para enfrentar a diversidade do desenvolvimento da sociedade da informação, é formar milhares e milhares de profissionais com um ensino de baixa qualidade, incapacitados e sem espírito crítico para romper as barreiras da desinformação. Portanto, uma formação de qualidade, jamais poderá ser aferida através de métodos quantitativos e/ou frameworks. Mas através do desenvolvimento intelectual, socioeconômico e cultural da população.

Palavras-chave: Ensino-aprendizagem a distância. Ambiente virtual. Certificado de qualidade.

\section{ABSTRACT:}

This article aim to describe about the repercussion and consequences of long distance education $(\mathrm{EaD})$. The sources used in this study were testimonials from Ead tutors, Their Experiences, Thematics and the techniques used in the courses, as well as, the achievements of the students of this modality. Recent studies Indicates to problematization of long distance education $(\mathrm{EaD})$, these in formations were utilized to strengthen the basis of this article. In this sence, Were Focused questionaments The Following: which are the Strengths and Weaknesses in EaD? What is the level of utilization by the students? This line of thought is Intended to show the Contribution of long distance education, which, taking many forms, Proposes new questions of institutional, social and pedagogical order. The method used was the quantitative Analisys. Considering that quantitative research is the most convenient way to deal with social issues, especially when there are, people, education, communication Involved. Therefore, it concludes that even with all technology used in Ead, this way of education / learning is still fragile in consequence of the large demand. In this conception, must step into the legacy of teaching certification as a subjective construct in the virtual ambient that is directly connected with the training and cognitive performance of citizens, who thus becomes in cultural capital. Because worse than a society unable to deal with the diversity of the development of information society is, graduating thousands and thousands of incompetent professionals each year because of low education level. Therefore a quality education will never be Reached through quantitative methods or / and frameworks.

Keywords: Distance education. Teaching and learning at distance. Quality 


\section{Introdução}

Construído sob a égide das tecnologias da informação e comunicação (TICs) a educação a distância converteu-se em uma das maiores ferramentas para a difusão do conhecimento e da informação, capaz de atender a todos os níveis, desde o básico até os níveis de especialização, mestrado e doutorado. Incluindo além dos programas de formação de ensino, diplomas e/ou certificados, cujo objetivo é oferecer capacitação para a melhoria no desenvolvimento das atividades profissionais dos sujeitos.

A Lei de Diretrizes e Bases da Educação Nacional (2006) em seus artigos apresenta como fundamental a flexibilidade do ensino e o respeito às iniciativas inovadoras que garantam a modalidade de educação a distância $(\mathrm{EaD})$ de qualidade e de forma igualitária para todos os cidadãos desde os mais longínquos espaços territoriais, assim como, a obrigatoriedade das instituições em planejar e programar sistemas de avaliação institucional, para o investimento em efetivas melhorias de qualidade coerentemente com o Sistema Nacional de Avaliação da Educação Superior (SINAES). A LDB prevê ainda que é de extrema importância a avaliação sobre o aproveitamento dos estudantes nesta modalidade, para que possa existir um indicativo sobre a qualidade do ensino, sobre o aproveitamento cognitivo do aluno, e a importância e utilização deste conhecimento para a sua vida laboral, e propõe que:

A avaliação da aprendizagem na EaD deve ajudar o estudante a desenvolver graus mais complexos de competências cognitivas, habilidades e atitudes, possibilitando-lhe alcançar os objetivos propostos. Para tanto, esta avaliação deve comportar um processo contínuo, para verificar constantemente o progresso dos estudantes e estimulá-los a serem ativos na construção do conhecimento. Desse modo, devem ser articulados mecanismos que promovam o permanente acompanhamento dos estudantes, no intuito de identificar eventuais dificuldades na aprendizagem e saná-las ainda durante o processo de ensino-aprendizagem. (Redação dada pela Lei 9.394, de 1996). (Brasil, 2007).

Estas propostas reúnem as necessidades básicas para associar o conhecimento à prática laboral, a fim de, atender a demanda da atual sociedade da informação e do conhecimento e das constantes mudanças que vem ocorrendo. Com base neste contexto é importante registrar a contribuição de Dourado (2007) em que o autor afirma que "[...] apesar do avanço das TICs existem ainda uma intensa precarização na formação do ensino a distância tanto de ordem institucional como pedagógica.”. 
$\mathrm{Na}$ perspectiva do sociólogo Jensen citado por Londoño (2010) afirma que "[...] o desenvolvimento de uma sociedade está relacionado com a interatividade dos sujeitos sociais e da necessidade que as pessoas têm de se relacionar umas com as outras e se adaptarem aos diversos contextos inter e multidisciplinares.”. Frey e outros (2000) afirmam que não basta apenas dominar as tecnologias, porque tão importante quanto este domínio é a transmissão e a difusão da informação e do conhecimento de forma coerente e eficiente para que apresentem resultados positivos, uma vez que esta modalidade envolve pessoas, profissionais, instituições e dinheiro público. E discorre ainda que:

O uso das ferramentas online denominada de "a quarta revolução" 4 é muito eficiente para o ensino-aprendizagem a distância porém quando bem administrada apresenta uma eficiente conveniência na comunicação, transmissão e na produção de conhecimento, além de abrir um leque de oportunidades para os usuários da informação.

Nesse sentido o autor expressa que existe a necessidade de associar a tecnologia com o saber e, conduzir a informação para formação de uma sociedade com espírito crítico, sintonizada com o mundo e interagindo com um conjunto de fatores provenientes das constantes e rápidas mudanças. Reafirma ainda que a introdução das tecnologias da informação e comunicação na educação promove a interação e novas formas de relações sociais, em consonância com novas configurações de produção de conhecimento dos sujeitos sociais. Além de vislumbrar novas formas de organização dos tempos, dos espaços e das relações educativas, apoiadas em recursos multimídia e, em novas formas de conceber as relações de ensino/aprendizagem, assim como, os papéis a serem desempenhados pelos atores da educação, com toda a diversidade derivada do acesso das pessoas, escolas e universidades, a fim de, atingir um patamar de democratização do acesso à informação e ao conhecimento.

\section{A educação a distância (EaD) na perspectivas das políticas públicas do Ministério da}

\section{Educação}

No Brasil, na década de 1990, em atendimento ao artigo 212 da Constituição Federal, ao artigo 60 dos Atos das Disposições Constitucionais Transitórias e às recomendações internacionais (da Declaração Mundial sobre a Educação para Todos) o governo passou a investir muito na expansão do ensino na modalidade a distancia de início para a educação básica, depois com a expansão para todos os níveis. Existiu, portanto por parte do governo o

\footnotetext{
${ }^{4}$ Segundo a UNESCO a quarta revolução da educação consiste na introdução de sistemas educacionais baseados em "open and distance learning (ODL)" e a utilização de Tecnologias de Informação e Comunicação (TICs) como ferramentas s essenciais nesse processo.
} 
investimento de vultosos recursos financeiros públicos para a capacitação de recursos humanos, na exigência de infraestrutura física e de suporte técnico para o funcionamento dos equipamentos e, a respeito da autonomia pedagógico-administrativa dos sistemas estaduais de ensino. Isto levou o MEC a propor o investimento descentralizado do programa, tornando-o flexível e contextualizado para o êxito destes investimentos. Nesse sentido as autoridades têm dedicado especial atenção para a sensibilização e à capacitação de recursos humanos, e à definição de estratégias que assegurem assistência didático-pedagógica nos processos de ensino e aprendizagem assim como a utilização de meios e tecnologias de informação e comunicação, com estudantes e professores desenvolvendo atividades educativas em lugares e/ou tempos diversos. E mais: o repasse direto de recursos às escolas e a ação de diretores que exercem o espaço de autonomia para definir o próprio projeto político-pedagógico, a fim de, produzir soluções personalizadas e criativas.

Decreto 5.622, de 19 de dezembro de 2005 define a educação a distância como modalidade educacional na qual a mediação didático-pedagógica deva ocorrer com a utilização de meios e tecnologias de informação e comunicação com estudantes e professores desenvolvendo atividades educativas em lugares ou tempos diversos. Porém deverá ser previsto a obrigatoriedade de um percentual de aulas presenciais para realização de avaliações dos estudantes, estágios obrigatórios, atividades relacionadas em laboratórios, bem como, a defesa de trabalhos para conclusão do curso. Estas e demais normas sobre o sistema do EaD, assim como, a emissão de certificados e diplomas que estão descritos nos artigos do referido Decreto. Portanto compete ao Ministério da Educação organizar, dirigir e padronizar os procedimentos para a execução da educação e aprendizagem.

Nessa perspectiva a crítica e analista Castra Neves (1996) afirma que a eficiência do $\mathrm{EaD}$ consiste não apenas na utilização das tecnologias da informação e comunicação (TICs) como principal instrumento para capacitar os sujeitos e/ou erradicar o analfabetismo no país, mas representa principalmente uma estratégia para dinamizar o ensino, elevar seu padrão de qualidade e instrumentalizar professores e alunos, desenvolvendo neles atitudes autônomas e críticas, fundamentais para viver num mundo onde aprender é uma exigência permanente. A essas razões juntam-se outras que justificam a significativa expansão da educação a distância: ela amplia oportunidades onde os recursos são escassos, permitindo uma educação mais equitativa e igualitária; familiariza o cidadão com tecnologias que estão no seu cotidiano; dá respostas flexíveis e personalizadas a uma diversidade cada vez maior de tipos de informação, 
educação e treinamento e; oferece meios de atualizar rapidamente o conhecimento técnico. Para cumprir essas funções, a educação a distância dispõe de equipamentos e infraestrutura cada vez mais baratos, acessíveis e de manejo mais simples. Segundo a autora as prioridades do MEC como órgão da União exerce a principal função de gestor desenvolvendo três funções básicas tais como: a oferta de suporte para garantir a qualidade e equidade do sistema nacional; fomento e apoio técnico ao desenvolvimento da educação e; coordenação e articulação do campo institucional. Sendo estes, os maiores desafios e prioridades do governo na contemporaneidade que é o investimento no ensino público a distancia nas redes publicas e privadas a nível estadual, municipal e federal. Assim como, analisar as experiências dos especialistas e, dar vez e voz aos professores, diretores, alunos e à comunidade, com o objetivo de ampliar as fronteiras do conhecimento, que é o objetivo da educação na modalidade a distância.

Dentro dos critérios de inclusão social através da modalidade de ensino a distância e/ou a denominada, quarta revolução educacional, o professor Araújo (2011) afirma que os profissionais da educação precisam entender e assumir uma postura acadêmico-científica que leve à reinvenção da educação. Esse modelo de escola e de universidade consolidado no século XIX tem agora também a responsabilidade de dar conta das demandas e necessidades de uma sociedade democrática, inclusiva, permeada pela diversidade e pautada no conhecimento inter, multi e transdisciplinar, como a que vivemos neste início de século XXI. E acrescenta que:

Esse processo de reinvenção, no entanto, precisa estar atento à tradição e à conservação, pois tais características são partes essenciais da missão social da educação, de conservar, transmitir e enriquecer o patrimônio cultural e científico da humanidade. Assim, essa busca por novas configurações educativas não pode ser concebida de maneira dicotômica, contrapondo tradição e inovação. O novo não se assenta sobre o vazio, e sim sobre as experiências milenares da humanidade.

Nesse sentido é essencial a construção de um ambiente virtual articulado com as mídias digitais, assim como, a participação de profissionais capacitados para interagir com os estudantes e atender ás suas necessidades, tanto na discussão no ambiente virtual, como nos encontros presenciais, para viabilizar a interface entre aluno e tutor, assim como tornar eficiente a prática do ensino/aprendizagem na modalidade a distância.

Considerando a dinâmica da EaD a professora, Rodrigues (2012) admite que esta modalidade $(\mathrm{EaD})$ é uma excelente ferramenta para uso educacional, pois possibilita ampliar o ensino para um maior número de alunos, apesar de, não haver o face a face 
(professor/aluno) há maior empenho do aluno, visto que ele mesmo é o responsável pelo gerenciamento de seu autoaprendizado. E nesse sentido o papel do tutor é dar apoio para que o aluno desenvolva o seu aprendizado e, possa criar dinâmicas e atividades pedagógicas inovadoras para melhorar o seu desempenho intelectual e cognitivo, para que se torne um transmissor da informação e do conhecimento no ambiente social. E acrescenta que: [...] quando se cogitou a implantação do ensino na modalidade a distancia $(\mathrm{EaD})$ na Fundação Joaquim Nabuco, se pensou na possibilidade de utilizar o potencial tecnológico disponível na instituição para capacitar, difundir a informação e conhecimentos com qualidade para atingir um maior número possível de pessoas nos diversos contextos sociais. Portanto os cursos que foram realizados pela FUNDAJ na modalidade a distancia, foram executados dentro do padrão de qualidade do MEC, e obteve excelente repercussão a nível nacional.

No escopo da política de democratização do ensino na modalidade a distancia o mestre e tutor de ensino a distância, Pinto (2012) discorre que a sociedade brasileira adentrou em novos desafios, e a educação como todos os demais setores precisam investir em tempo e dinheiro no intuito de capacitar a população estudantil e profissional para que estes possam fluir e andar lado a lado no novo cenário da sociedade da informação. E acrescenta ainda que, para atender ao novo contexto da modalidade de ensino a distancia $(\mathrm{EaD})$ direcionado para a capacitação de jovens e profissionais a FUNDAJ através do núcleo de educação a distância vem realizando desde 2010 diversos cursos nesta modalidade de curta e longa duração para potencializar esses profissionais para o mercado laboral e/ou acadêmico. E dentre os cursos que se destacaram neste período foram: Explorando o Universo da EaD, que foi realizado no período de 2010-2011 e; Educação a Distancia em Foco, que tem previsão para ser realizado no segundo semestre de 2012. Segundo o tutor Alexandre Pinto estes cursos foram de grande valia e aproveitamento para os estudantes participantes. E de acordo com os resultados positivos alcançados nesse período a FUNDAJ pretende investir em novos cursos a distância para os próximos semestres, a fim de, dar continuidade a sua missão de fornecer conhecimentos técnicos para o fortalecimento da pesquisa e do desenvolvimento do estado de Pernambuco, da região Nordeste e do Brasil.

Nesse contexto considera-se que a educação a distância para cumprir sua função de mediadora do conhecimento, ela amplia oportunidades onde os recursos são escassos, permitindo uma educação mais equitativa, disponibiliza equipamentos e infraestrutura cada vez mais baratos, acessíveis, além de familiarizar o cidadão com tecnologias que estão no seu 
cotidiano; dá respostas flexíveis e personalizadas a uma diversidade cada vez maior de tipos de informação, educação e treinamento; e oferece meios de atualizar rapidamente o construto pessoal e profissional. Outra face positiva da $\mathrm{EaD}$ é a diminuição das distâncias territoriais, uma vez que, concede a chance de pessoas que moram em lugares isolados ou afastados dos locais de apreender novos conhecimentos e, frequentar cursos de graduação e pós-graduação que são ofertados por diversas instituições públicas e privados consideradas centros de excelência acadêmica, sem que, com isso necessitem se deslocar do local de trabalho ou mesmo da residência.

Segundo os indicadores do Instituto de Desenvolvimento Humano - IDH (2007-2008), órgão do governo que mede o nível de desenvolvimento humano no país a partir de indicadores de educação, indica que existe um acentuado crescimento do acesso de estudantes ao nível superior, particularmente na modalidade de ensino a distância (EaD). Sem duvida alguma, é impossível desconhecer o empenho das políticas do governo para atender a demandada da educação a distância, os esforços em aumentar seu raio de ação para ampliar as fronteiras do conhecimento, enfrentando como desafio cada vez mais contemporâneo da sociedade brasileira. Mas paralelo a este conceito sobre o crescente desenvolvimento desta modalidade nas instituições de ensino publicas e privadas, assim como, crescimento do acesso de estudantes que optam por esta modalidade de ensino, os especialistas do IDH ressaltam que existe ainda inúmeros pontos negativos que devem ser corrigidos pelo governo tais como: a ausência física de professores qualificados para ministrar as aulas tanto na modalidade online, como semipresenciais, assim como, professores capacitados, despojados para ajudar o aluno; vínculos afetivos necessários para a plena realização do processo de ensino-aprendizagem, uma vez que, toda aprendizagem precisa estar calcada em um bom relacionamento interpessoal entre o professor e os aprendizes; as deficiências de compreensão dos alunos decorrente da falta de leitura, o elevado índice de evasão em consequência de diversos fatores como: o econômico, social, a distancia entre a plataforma de ensino e o aluno, que faz gerar ruído na transmissão da informação; desperdício de recursos, lembrando casos em que equipamentos que se tornam obsoletos e sem uso nas escolas, porque os professores não sabem operá-los, ou não são capacitados e treinados para explanar aulas na referida modalidade, muitas vezes as maquinas necessitam de manutenção, os altos custos dos cursos, somando-se aos fatores mais angustiantes nesta questão que são os salários dos professores, os principais atores sociais no contexto da sociedade da informação e do conhecimento. 
Porque estes profissionais são a mola, ou melhor, a ferramenta própria para disseminação da informação, assim como, elevar o nível de conhecimento da sociedade. O não reconhecimento desses sujeitos faz gerar um retrocesso da sociedade da informação que pode se equiparar ao modelo da sociedade medieval, em que a informação era privilégios para alguns e o conhecimento era guardado a chave. Porque tanto a carência de professores qualificados, como professores mal pagos e/ou insatisfeitos com seus salários tornam-se os precedentes para uma descontinuidade do investimento para a educação, tanto presencial, como na modalidade a distancia. Esta falta de respeito com os profissionais da educação, além de contribuir em grande parcela para o desgaste da profissão de professor, reflete diretamente para a formação de profissionais incompetentes e descapacitados, além de favorecer o atraso dos estudantes, e contribuir para queda da qualidade do ensino. Estas e demais outras deficiências observadas são a realidade de nossa sociedade que deve ser levada ao conhecimento das autoridades que fomentam esses recursos, para que sejam corrigidas a fim de, tornarem o EaD uma modalidade eficiente e que passe a gerar índices positivos na obtenção de uma educação não somente inclusiva, mas um ensino de qualidade.

\section{A face oculta do EaD na perspectiva do Instituto de Desenvolvimento Humano-IDH}

Levando em consideração os índices deficitários do EaD alcançados nos últimos anos, segundo os dados do IHD, trazemos para esta discussão alguns estudos realizados por diversos especialistas e críticos para a problematizaçao deste tema. Dentre inúmeros comentários muitos especialistas alinhados ao discurso do governo federal afirmam que o uso das tecnologias da informação e comunicação (TICs) é a plataforma em que deve estar situada a EaD no Brasil, que esta é a ferramenta própria para promover a ampla e irrestrita inclusão social cuja responsabilidade de tais arquétipos está a cargo desta modalidade, que chega onde escola nenhuma chegou e permite às pessoas, sabidamente excluídas, permite que estas comunidades excluídas alcancem o tão sonhado acesso ao conhecimento e aos diplomas nos diversos níveis, assim como, a garantia da possibilidade quase instantânea de ascensão econômica.

Porém, há, no entanto, alguns críticos que discutem também sobre esta temática, apoiam o sucesso deste empreendimento, mas têm a ousadia de irem um pouco mais longe, quando afirmam que o ensino a distancia não é tão barato, nem tão fácil como se comentam. 
Dourado e outros (2002) afirmam que esta tese realmente é verdadeira quando parte para a necessidade de treinamento de professores, disponibilidade de horário, infraestrutura de ambiente informatizado, bibliografia e outros materiais didáticos necessários para o ensinoaprendizagem, da mesma forma como se fossem realizar aulas de cursos presenciais. E sem falar na responsabilidade que tem a instituição que realiza esta modalidade de ensino, pois entra em jogo além dos vultosos custos, o nome da instituição ao aferir certificados às pessoas que às vezes, nem se quer as conhecem, tão pouco, se sabe se estas pessoas estão realmente capacitadas, aptas para atender aos requisitos de uma aprendizagem de qualidade e para o recebimento do certificado e/ou diploma. Quais os indicativos que tem estas instituições para controlar e medir o nível de conhecimento adquirido pelos alunos nestes cursos a distância? Onde está o controle dos órgãos do governo para creditar um ensino de qualidade? Nesse sentido os autores assinalam que esta invenção é mais uma faceta do desmantelamento do dinheiro público, e que a educação a distância vem sendo mais um alvo no Brasil. Basta, portanto, verificar que o PROUNI teve uma expansão muito rápida, usando como referência, a transferência de dinheiro público para a iniciativa privada, permitindo, assim, um crescimento sem precedentes das instituições privadas de ensino superior. Nesta armação além de encher o cofre das instituições privadas e garantir a expansão física destas unidades, estas instituições ainda lucram pela venda do produto (educação a distancia) aos seus consumidores (a sociedade). Na realidade estes cursos custam muito caro para o bolso dos estudantes e, não possuem um certificado de qualidade. Dourado discorre ainda que:

Outro fator preocupante do EaD é a imposição de subcategorias de docentes, que passam a atender por monitores, tutores, orientadores e outras denominações semelhantes. Tal como ocorre há tempos na educação básica: professores que são referidos como: tias, auxiliares, recreadores, facilitadores... Para reiterar definitivamente a máxima de Paulo Freire "Professora sim, tia não". Não parece razoável que uma categoria profissional tão desrespeitada, como a dos professores, admita a criação de subcategorias que em breve poderão também ser a daqueles que hoje ainda atendem por professores, mas cujas condições de trabalho podem - dentro da lógica do capital - ser sempre um pouco mais precarizada. O EaD é uma modalidade de educação que só serve aos interesses mais espúrios do capitalismo e assim, precisa ser encarado pelos professores e professoras que - pressionados ou não nesse momento - veem a sombra da tal tecnologia sobre suas costas. Serve ao capitalismo na medida em que torna a educação mais um item mercadológico restrito a números que nada dizem, esvazia de significado a profissão docente do mesmo modo que esvazia de significado a educação, pois quer fazer crer que nela há uma propriedade maligna: o professor.

Obedecendo a essa lógica, a educação, a exemplo de outros produtos, é mais uma mercadoria estranha à venda nas prateleiras, como por exemplo: o café descafeinado, o cigarro sem nicotina, o leite sem gordura, a cerveja sem álcool, o sexo virtual - sexo sem sexo. 
Portanto a erradicação da desinformação e da descapacitação, assim como, do analfabetismo, do desemprego, da extrema miséria e da fome é uma constante utopia inserida no seio da sociedade brasileira, desde que esta, tornou-se civilizada o povo vive ainda a sonhar por uma civilização fantástica, idealizada dentro dos padrões de uma sociedade socialmente, economicamente e culturalmente desenvolvida. Na verdade, isto é uma luta histórica do povo brasileiro em busca da conquista de seus direitos como cidadãos. E a luta pela educação de qualidade e pública precisa ser evocada nesse momento para que possam resistir e impedir que o governo federal e, especificamente o MEC, continue autorizando e incentivando estes desmandos que vem sendo a marca das políticas de governo anos a fio, sem um devido controle da eficiência da educação.

\section{Desafios para o controle de qualidade do EaD: uma problemática internacional}

Antes de conceituar os princípios adotados pelos cientistas da informação para o controle de qualidade do $\mathrm{EaD}$ é necessário considerar que a atividade de ensino/aprendizagem, seja ela presencial e/ou a distancia, é um produto valioso oferecido a sociedade e, este por sua vez, deve ser mantido dentro do nível aceitável do padrão de qualidade de uma educação eficiente.

Para Feigenbaum (1956) o termo controle da qualidade de um produto consiste na observação dos seguintes itens: orientação ao cliente, qualidade em primeiro lugar, ações orientadas por prioridades, fatos e dados, controle de processos e da dispersão (variação dos dados que indicam quando há uma possível falha no processo) e, investigação das causas através de seus clientes, identificando as verdadeiras necessidades dos clientes, afim de, evitar que erros já identificados sejam cometidos novamente. E esse controle de qualidade somente será alcançado quando essa tarefa é realizada em conjunto com todos os envolvidos no desempenho da organização. E discorre ainda que, o controle da qualidade deva analisar também as condições em que o produto é produzido; como é produzido, para qual público que está sendo produzido; os efeitos colaterais que este produto poderá ocasionar e, portanto, a eficácia deste produto para o público alvo. Portanto este produto antes de entrar no mercado de consumo ele deve ser testado e apresentar o risco de defeitos-zero. Após o consumo deste produto pela comunidade, deverá ser avaliado o nível de satisfação do público usuário, que deverá atingir o nível excelente de satisfação do referido produto. A partir daí sim, este produto poderá receber o certificado de garantia de qualidade. 
Nesse sentido para garantir a qualidade do ensino/aprendizagem no EaD, Kirkpatrick citado por Bossu (2010) afirma que deve existir uma avaliação sob diversos aspectos e que envolva desde o valor, a qualidade e a transmissão da informação, o material didático, o desenvolvimento de políticas institucionais, capacitação do corpo docente e principalmente o desempenho do aluno que é o caráter cognitivo e/ou uma eficiente aprendizagem, que é o que se espera obter na conjuntura do $\mathrm{EaD}$. Por isso, tanto o valor da transmissão da informação, assim como, o material didático utilizado devam auxiliar para a análise, com ênfase no construto cognitivo do estudante e, estes efeitos só podem ser apreendidos por análises qualitativas, em que o resultado deste estudo deva apresentar um índice aceitável dentro das estimativas de eficácia, que pode ser comprovado por um índice de ruídos-zero ${ }^{6} \mathrm{Na}$ estimativa do autor ele quer dizer que "[...] o ensino no ambiente virtual deve ser realizado dentro dos padrões de equilíbrio entre a transmissão da informação e, a eficiência na capacitação do estudante, para que impliquem em resultados efetivamente positivo.”.

Saracevic (1996) afirma que a eficiência na transmissão da informação (ensino/aprendizagem) engloba a ideia de uma informação de qualidade. Levando este conceito para analisar a qualidade do $\mathrm{EaD}$ significa dizer que deve existir por parte dos especialistas um grau de adequação na transmissão da informação com a finalidade de solucionar o problema do sujeito-usuário-receptor da informação, a fim de contribuir para um resultado positivo no processo cognitivo do aluno, ou melhor, obter como resultado o sujeito eficientemente qualificado.

Judith Eaton (2002) presidente do Conselho de Educação Superior de Acreditação dos Estados Unidos responsável pela avaliação da qualidade do ensino a distancia discorre que para atender a demanda e os desafios para o controle de qualidade do $\mathrm{EaD}$, deve-se chamar a atenção dos responsáveis da educação a distancia para que além da observância às leis que regulamentam esta modalidade de ensino, trabalhem para a criação de organismos e/ou agências para fiscalização e controle destas ações. Estas agências devem ter por principio fazer cumprir as exigências das políticas de ensino e aprendizagem, a fim de que, estas

\footnotetext{
${ }^{5}$ O caráter cognitivo ou cognição do sujeito é a forma como o cérebro percebe, aprende, recorda e pensa sobre toda informação captada através dos cinco sentidos. É o conjunto dos processos mentais usados no pensamento e na percepção, também na classificação, reconhecimento e compreensão para o julgamento através do raciocínio para o aprendizado de determinados sistemas e soluções de problemas.

${ }^{6}$ Ruído-zero e/ou precisão da informação igual a 100\% (ou variância do erro nula).
} 
atividades atendam tanto os critérios estabelecidos pelas políticas de acesso à informação e à educação a distancia, assim como, na qualidade deste ensino para uma eficiente capacitação da população estudantil.

Sobre os referenciais de controle de qualidade para a educação a distancia Bowden e Marton citado por Bossu (2010) afirmam que "[...] a grande maioria dos países desenvolvidos tais como Estados Unidos da América, Austrália, Canadá e Reino Unido utilizam os frameworks ${ }^{7}$ que é uma ferramenta importante para identificar as instituições credenciadas para realizar o $\mathrm{EaD}$, e de acordo com os resultados obtidos a partir destas avaliações as universidades tornam-se auto-creditadas, isto é adquirem autonomia para gerenciar, criar, renovar, melhorar, manter e/ou remover cursos tanto presenciais como a distancia.”.

No Brasil o framework desenvolvido para a análise e regulação do $\mathrm{EaD}$, foi criado pelo Ministério de Educação (MEC) juntamente com a Secretaria de Educação a Distancia (SEAD) denominado de Referencial de Qualidade para a Educação Superior a Distancia, este sistema estabelece os critérios para aprovar e creditar as instituições para a oferta de EaD. Porém alguns especialistas do próprio Ministério de Educação admitem que estes critérios sejam frágeis e superficiais, permitem apenas uma avaliação para mapear as instituições credenciadas e a prestação de contas do dinheiro publico utilizado por estas instituições, mas não garantem o controle da qualidade no EaD.

Em uma investigação realizada pela pesquisadora australiana Carina Bossu (2010) para analisar a eficiência do Referencial de Qualidade para a Educação Superior a Distancia no Brasil a investigadora afirma que:

No Brasil não existe documentos que demonstrem que os referenciais contribuam para promover um ensino de qualidade nos programas de EaD. Pelo contrário, a forma de como estes referenciais estão sendo adotado pelas instituições do Ministério de Educação, parecem motivar somente a prestação de contas, ao invés da melhoria do ensino na modalidade EaD. Foi verificado também que alguns materiais didáticos utilizados nos cursos a distancia são simplesmente uma adaptação rudimentar dos materiais usados no ensino presencial.

Nesse contexto, Campos e outros (2007) afirmam que o EaD pode ser visto como um sistema de ensino positivo para o desenvolvimento da autonomia da aprendizagem, pois permite que o estudante assimile o conhecimento em seu próprio ritmo. Mesmo com esta liberdade de aprendizagem que oferece o $\mathrm{EaD}$, esta forma de aquisição de conhecimento deve ser verificada através de uma análise qualitativa, a fim de, evitar que esses alunos

\footnotetext{
${ }^{7}$ Framework é um conjunto de classes que colaboram para realizar uma responsabilidade para um domínio de um subsistema da aplicação. (FAYAD e SCHMIDT, 1997).
} 
permaneçam mergulhados em suas próprias incógnitas, que na maioria das vezes, eles próprios desconhecem. Este termo utilizado por Campos (2007) e diversos autores corroboram com efetiva fragilidade do $(\mathrm{EaD})$.

\section{Considerações finais}

De acordo com o que foi exposto neste artigo, entende-se que existe uma grande preocupação internacional que assolam diversos países, tanto os desenvolvidos como os emergentes em estabelecer diretrizes e políticas de gestão do ensino/aprendizagem na modalidade de ensino a distancia como forma de democratização e inclusão social.

Apoiamo-nos, portanto nestes diversos conceitos, inclusive no discurso de Dourado e outros (2006) em que estes especialistas sugerem a criação de uma agencia reguladora que possa atuar juntamente com o MEC como mediador para certificar a qualidade do ensino/aprendizagem dos estudantes na modalidade EaD. Considerando que a eficiência da transmissão da informação, assim como a efetiva educação não podem ser avaliados por pressupostos eletrônicos e/ou métodos estatísticos que apontam a quantidade de estudantes que estão inseridos, ou a quantidade de estudantes que abandonaram os cursos de programas de ensino a distancia. Estes métodos aferem apenas os gastos vultosos do governo com a implantação de setores informatizados e na creditação e autorização das instituições sejam publicas ou privadas para que estas possam adotar esta modalidade de ensino e, para que possam se utilizar dos benefícios do dinheiro público. Estas instituições além de se utilizarem dos benefícios do governo para implantação e inovação de suas estruturas acadêmicas, ainda vendem a informação por preços altíssimos e sem o compromisso de certificar a qualidade do ensino/aprendizagem e/ou à transferência da informação que está sendo negociada.

Portanto a lógica para a emissão do certificado de qualidade do ensino/aprendizagem do $\mathrm{EaD}$, na nossa concepção deve está centrada na teoria do sociólogo francês, Pierre Bourdieu (1980) em que o autor afirma que “[...] a escola é um espaço de reprodução de estruturas sociais e de transferência de capitais (conhecimento) de uma geração para outra, e que esta deva estar comprometida em instigar o espírito crítico do cidadão.”. Portanto a visão e a preocupação dos especialistas da educação deva estar centrada em provocar o novo. É dizer, capacitar o sujeito para que ele seja um crítico e, possa dar sua contribuição para a 
construção de uma sociedade melhor. É nesta concepção que deve centrar o legado da certificação do ensino/aprendizagem como um construto subjetivo que está diretamente relacionado tanto ao desenvolvimento cognitivo, como ao desempenho dos estudantes e, que de certa forma, transforma-se em capital cultural. E este legado jamais poderá ser aferido através de métodos quantitativos e/ou frameworks, porque o conhecimento não é um produto concreto e palpável, mas poderá ser investigado e identificado sobre sua eficiência e/ou deficiência através de análises aplicadas à população investigada utilizando métodos qualitativos.

Cabe, portanto aos ilustres representantes do governo a elaboração de um projeto estratégico para investir em melhorias, a fim de, sanar a atual fragilidade do sistema EaD no Brasil. Assim como, investir na criação de uma agência reguladora ${ }^{89}$ para esta modalidade de ensino, para que se possa ter uma visão global, atual e futura deste sistema, bem como, conviver com as incertezas, a fim de, buscar soluções adequadas para tornar o EaD uma ferramenta realmente eficiente para alavancar o desenvolvimento da sociedade brasileira. Não se esquecendo de levar em consideração o que já dizia Bourdieu (2003) sobre a utilização dos recursos tecnológicos para uma eficiente educação “[...] quanto mais um campo é heterônomo, mais a concorrência é imperfeita e torna-se mais lícito para os agentes fazer intervir forças não científicas nas lutas científicas. Portanto para fazer valer os objetivos e as pressões sociais de forma lógica é preciso fazer triunfar argumentos, demonstrações e refutações.".

\section{Referências Bibliográficas}

1. ARAGON, Glauca Torres. Desempenho de estudantes de diferentes municípios em uma disciplina do ensino superior a distancia. Revista EAD em Foco, Rio de Janeiro, v.1, n.1, p.69-77, abr./out. 2010.

\footnotetext{
${ }^{8}$ As Agências Reguladoras são criadas através de Leis e tem natureza de Autarquia com regime jurídicoespecial. Consistem em instituições com poderes especiais, integrantes da administração pública indireta, que se dispõe a fiscalizar e regular as atividades de serviços públicos executados por empresas privadas, mediante prévia concessão, permissão ou autorização. Estas devem exercer a fiscalização, controle e, sobretudo, poder regulador incidente sobre serviços delegado a terceiros. E estão sujeitas ao mesmo tratamento das autarquias e passíveis de idênticos mecanismos de controle
} 
2. ASSOCIAÇÃO BRASILEIRA DE NORMAS TÉCNICAS. NBR 6023: informação e documentação: referencias: elaboração. Rio de Janeiro, 2002.

3. ASSOCIAÇÃO BRASILEIRA DE NORMAS TÉCNICAS. NBR 10520: informação e documentação: citações em documentos: apresentação. Rio de Janeiro, 2002.

4. ASSOCIAÇÃO BRASILEIRA DE NORMAS TÉCNICAS. NBR 14724: informação e documentação: trabalhos acadêmicos: apresentação. Rio de Janeiro: ABNT, 2011.

5. ASSOCIAÇÃO BRASILEIRA DE NORMAS TÉCNICAS. NBR 6024: numeração progressiva das seções de um documento escrito: apresentação. Rio de Janeiro: ABNT, 2003.

6. ASSOCIAÇÃO BRASILEIRA DE NORMAS TÉCNICAS. NBR 6027: informação e documentação: sumário: apresentação. Rio de Janeiro: ABNT, 2003.

7. ASSOCIAÇÃO BRASILEIRA DE NORMAS TÉCNICAS. NBR 6028: informação e documentação: resumo: apresentação. Rio de Janeiro: ABNT, 2003.

8. ASSOCIAÇÃO BRASILEIRA DE NORMAS TÉCNICAS. NBR 6029: informação e documentação: livros e folhetos: apresentação. 2. ed. Rio de Janeiro: ABNT, 2006.

9. ASSOCIAÇÃO BRASILEIRA DE NORMAS TÉCNICAS. NBR 6032: abreviação de títulos de periódicos e publicações seriadas. Rio de Janeiro: ABNT, 1989.

10. BOURDIEU, Pierre. Os usos sociais da Ciência por uma sociologia clínica do campo científico. São Paulo: UNESP, 2003.

11. BOWDEN, J. ; Morton, F. The University of Learning: beyond quality and competence. New York: Rutledge Falmer, 2003.

12. BOSSU, Carina. Qualidade na educação a distância no ensino superior brasileiro: prestação de contas ou melhoria. Disponível em: <uneau.academia.edu/CarinaBossu/.../Qualidade_na_educacao_superior>.Acesso em: 17 jul. 2012.

13. BRASIL. Decreto No. 5.622, de 19 de dezembro de 2005. Regulamenta o art. 80 da Lei $\mathrm{n}^{\circ}$ 9.394, de 20 de dezembro de 1996. Disponível em: <www.planalto.gov.br/ccivil_03/_...2006/2005/decreto/D5622.htm>. Acesso em: 27 jul. 2012

14. BRASIL. Decreto N. ${ }^{\circ}$ 5.773, de 09 de maio de 2006, dispõe sobre o exercício das funções de regulação, supervisão e avaliação de instituições de educação superior e cursos superiores de graduação e sequenciais no sistema federal de ensino. Disponível em: 
<www.planalto.gov.br/ccivil_03/_...2006/2005/decreto/D5622.htm>. Acesso em: 27 jul. 2012.

15. BRASIL. Decreto N. ${ }^{\circ}$ 6.303, de 12 de dezembro de 2007, altera dispositivos dos Decretos nos 5.622, de 19 de dezembro de 2005, que estabelece as diretrizes e bases da educação nacional, e 5.773, de 9 de maio de 2006, que dispõe sobre o exercício das funções de regulação, supervisão e avaliação de instituições de educação superior e cursos >.Acesso em: 27 JUL. 2012.

16. BRASIL. Ministério da Educação. Plano de Desenvolvimento Institucional 2010-2014: MEC, 2009. Disponível em: <http://www.ufrb.edu.br/portal/documentos/category/2documentos?...>

17. CAMPOS, Fernanda. SANTOS, Neide. COSTA, Ilaim. Coordenação e tutoria em curso de capacitação em EAD para o Sistema UAB: Relato de uma Experiência. In: Simpósio Brasileiro de Informática na Educação, 19, 2008, Rio de Janeiro- RJ. Anais... Rio de Janeiro: UERJ, 2008, p.187-197. ano 7, n. 54, 1 fev. 2002. Disponível em: <http://jus.com.br/revista/texto/2654>. Acesso em: 26 jul. 2012.

18. CARVALHO, Cristiano Martins de. Agências reguladoras. Jus Navigandi, Teresina, ano 7, n. 54, 1 fev. 2002. Disponível em: < http://jus.com.br./revista/texto/2654>. Acesso em: 26.jul.2012.

19. CASTRA NEVES, Carmen Moreira. O desafio contemporâneo da educação. Em Aberto, Brasília, a.16, n.70, p. 34-41, abr.jun.1996.

20. DOURADO, L. Políticas de expansão da educação superior no Brasil e a modalidade EAD. In: SEMINÁRIO NACIONAL UNIVERSITAS/BR, 14, 2007, Brasília. Educação Superior no Brasil e diversidades regionais, 2007.

21. EATON, Judith S. Council for Higher Education Acreditation. Disponível em: <www.chea.org/About/Eaton.asp>. Acesso em: 18 jul.2012.

22. FEIGENBAUM, Armand V. Controle de qualidade total. São Paulo: Makron Books, 1994.

23. FREIRE, Gustavo Henrique. Ciência da informação: temática, histórias e fundamentos. Perspectiva Ciência da Informação. Belo Horizonte, v.11 n.1, p. 6-19, jan./abr. 2006. Disponível em: <http://www.scielo.br/pdf/pci/v11n1/v11n1a02.pdf.>. Acesso em 12 jul. 2012. 
24. FREY, K. Políticas públicas: um debate conceitual e reflexões referentes à prática da análise de políticas públicas no Brasil. Instituto de Pesquisa Econômica Aplicada, Brasília, v. 21, p. 211-259, 2000. Disponível em: <http://www.ipea.gov.br>. Acesso em: 25 jul. 2012.

25. JENSEN, J. J. Self-Organized Criticality: Emergent complex behavior in physical and biological systems. Cambridge: Cambridge University Press, 1998.

26. LIMA, Marcos Antonio Martins. Avaliação de programas nos campos da educação e da administração: ideias para um projeto de melhoria ao modelo de Kirkpatrick. Revista Electrónica Iberoamericana sobre Calidad, Eficacia y Cambio en Educación, México, Vol. 5, n. 2. 2007. Disponível em: 〈http://www.redalyc.uaemex.mx/src/inicio/ArtPdfRed.jsp?iCve=55150214 >. Acessado em 25 jul. 2012.

27. LONDOÑO OCAMPO, León P. ¿Es lo mismo el aprendizaje y la memoria? Hacia una amplia conceptualización. Revista de la Facultad de Psicología Universidad Cooperativa de Colombia, v. 4, n. 6 - 7,/ enero/ dic. 2008. Disponível em: < http://web.ucc.edu.co/.../files/.../articulo-08-vol4-n6-7.p.>. Acesso em: 20 jul. 2012.

28. NÓVOA, Antônio. Profissão professor. Porto: Porto Editora, 1995.

29. RODRIGUES, Sandra Helena; PINTO, Alexandre. Explorando o universo do EaD. Disponível em: <eadfundaj. blogspot.com>. Acesso em: 12 jul.2012.

30. SEGENREICH, Stella Cecília Duarte. Pro Uni e UAB como estratégias de EAD na expansão do Ensino Superior. Pro-Posições, Campinas, v. 20, n. 2, maio/ago. 2009. Disponível em: www.scielo.br/pdf/pp/v20n2/v20n2a13.pdf. Acesso em 16 jul.2012.

31. TEFCO. Saracevic. Ciência da Informação: origem, evolução e relações. Perspectiva Ciência da Informação, Belo Horizonte, v.1, n.1, jan./jun. Disponível em:

32. <http: //www.portaldeperiodicos.eci.ufmg.br/index.php/pci/article/view/235>. Acesso em: 12 jul.2012. 